\title{
Kinetic Studies on the Nucleophilic Substitution Reaction of 4-X-Substituted-2,6-dinitrochlorobenzene with Pyridines in MeOH-MeCN Mixtures
}

\author{
Ryun Youn Sung, Hojune Choi, Jong Pal Lee, ${ }^{\dagger *}$ Jong Keun Park, Kỵull Yang, and In Sun Koo \\ Department of Chemistry Education and Research Institute of Natural Science, Gveongsang Kational Lniversity. \\ Gyeongsang, Jinju 660-701, Korea. E-mail: iskooiăgnuac.kr \\ ${ }^{\dagger}$ Department of Chemistry Dond-A Universitv, Pusan 604-714, Korea \\ Received Mav 21, 2009, Accepted Mav 26, 2009
}

\begin{abstract}
The reaction rates of $4-\mathrm{X}-2,6$-dinitrochlorobenzenes $\left(\mathrm{X}=\mathrm{NO}_{2}, \mathrm{CN}, \mathrm{CF}\right.$ ) with $\mathrm{Y}$-substituted pyridines $\left(\mathrm{Y}=3-\mathrm{OCH}_{3}\right.$, $\mathrm{H}, 3-\mathrm{CH}_{3}, 4-\mathrm{CH}_{3}$ ) in methanol-acetonitrile mixtures were measured by conductometry at $25^{\circ} \mathrm{C}$. It was observed that the rate constant increased in the order of $\mathrm{X}=4-\mathrm{NO}_{2}>4-\mathrm{CN}>4-\mathrm{CF}_{3}$ and the rate constant also increased in the order of $\mathrm{Y}=4-\mathrm{CH}_{3}>3-\mathrm{CH}_{3}>\mathrm{H}>3-\mathrm{OCH}_{3}$. When the solvent composition was varied, the rate constant increased in order of $\mathrm{MeCN}>50 \% \mathrm{MeOH}>\mathrm{MeOH}$. The electrophilic catalysis by methanol may be ascribed to the fomation of hydrogen bonds between alcoholic hydrogen and nitrogen of pyridines in ground state. Based on the transition

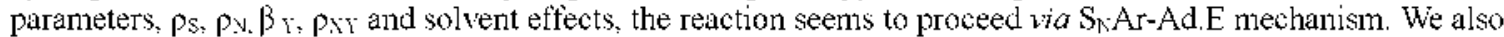
estimated the isokinetic solvent mixtures ( $\rho_{\mathrm{xy}}=0$ ) based on cross-interaction constants, where the substituent effects of the substrate and nucleophile are compensated
\end{abstract}

Key Words: Hydrogen bond. S.Ar-Ad.E mechanism. Cross-interaction constants. Isodielectric solvents. Isokinetic solvent mixtures

\section{Introduction}

Nucleophilic aromatic substitution reactions are known to undergo through three possible mechanisms: (i) bimolecular nucleophilic aromatic substitution. $\mathrm{S}_{\mathrm{N}} \mathrm{Ar}-\mathrm{Ad}$.E accompanying the formation of Meisenheimer $\sigma$-comple ${ }^{l}$ as an intermediate (addition-elimination pathway). ${ }^{3}$ (ii) elimination-addition process. S.Ar-E.Ad or $\mathrm{S}_{\mathrm{N}} \mathrm{LAr}$ (similar to a $\mathrm{S}_{\mathrm{N}} \mathrm{l}$ mechanism). which is more rare and is referred to as the unimolecular mechanism. ${ }^{2.3}$ In this mechanism, the elimination of leaving group is already completed at the time of the nucleophilic attack. (iii) bimolecular concerted aromatic nucleophilic substitution $S: 2 \mathrm{Ar}$ (similar to a $\mathrm{S}_{\mathrm{N}} 2$ mechanism). "In this mechanism. the elimination of the leaving group and the addition of the nucleophile occur more or less simultaneously without formation of an intermediate.

However nucleophilic aromatic substitution reaction of aromatic compounds having strong electron withdrawing substituents with amines generally involves the $\mathrm{S}_{\mathrm{N}} \mathrm{Ar}$ mechanism (eq 1$)^{4.5}$

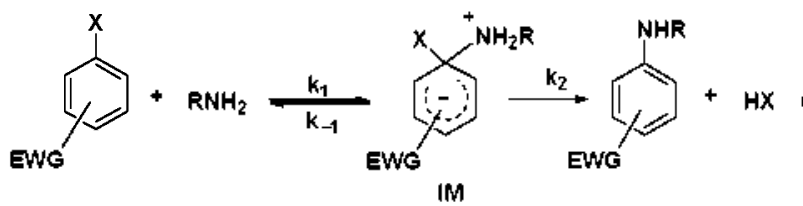

EWG $=$ electron-withdrawing group

Many researchers have interested in the nature of specific solvent effects on the nucleophilic aromatic substitution in isodielectric solvents such as methanol-acetonitrile mixtures. ${ }^{6 . ?}$ Rates of reactions between polar molecules are quite insensitive to the change from dipolar aprotic to protic solvent of the same dielectric constant when there exists only electrostatic interactions between reactants (or transition states) and solvents. the rate is remarkably changed in the same solvent transfer. ${ }^{6.8}$

Reaction mechanism, reactivity and solvents effects in these systems have been examined extensively ${ }^{9-11}$ and we have recently studied the displacement reaction of strongly activated aromatic compounds by anilines of chloride in methanol-acetonitrile solvents. ${ }^{12}$ This study showed that the N-C bond forning step made a great contribution to the overall second order rate constant. However. it was found that the electrophilic cataly sis by methanol probably resulted from the hydrogen bonding between alcoholic hydrogen and leaving chloride in the transition state. ${ }^{12}$ Therefore. mechanistic study on the nucleophilic substitution reaction between aromatic compounds having strong electron withdrawing substituents and amines is very important in examining the effects of protic solvent in the ground state or transition state. In this work, we determined the second-order rate constants for the reaction of 4-X-substituted-2.6-dinitrochloro benzenes (SDC. eq 2) with Y-substituted pyridines in methanol-acetonitrile nuixtures at $25^{\circ} \mathrm{C}$.

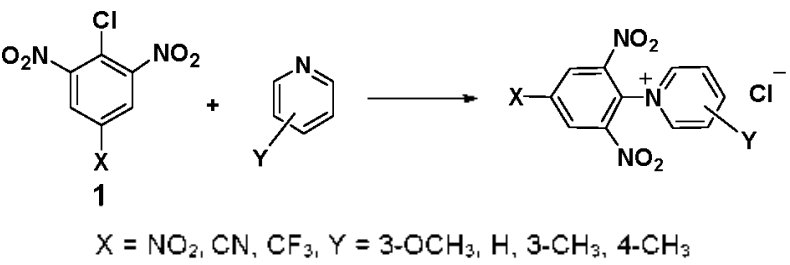

In order to discuss the reaction mechanism and solvent effects. we determined transition state parameters, $\rho_{\mathrm{X}} . \rho_{\mathrm{Y}} \beta_{\mathrm{Y}}$ using Hammett and simple Brönsted relationships, and the cross-interaction constants. ${ }^{13.14}$ pxy in eq 3, where $X$ and $Y$ are substituents in the substrate and nucleophile, respectively. 


$$
\begin{aligned}
& \log \left(\mathrm{k}_{\mathrm{XY}} / \mathrm{k}_{\mathrm{HH}}\right)=\rho_{\mathrm{X}} \sigma_{\mathrm{X}}+\rho_{\mathrm{Y}} \sigma_{\mathrm{Y}}+\rho_{\mathrm{YY}} \sigma_{\mathrm{X}} \sigma_{\mathrm{Y}} \\
& \rho_{\mathrm{XY}}=\partial \rho_{\mathrm{Y}} / \partial \sigma_{\mathrm{Y}}=\partial \rho_{\mathrm{Y}} / \partial \sigma_{\mathrm{Y}} .
\end{aligned}
$$

\section{Results and Discussion}

The present reactions obeyed the kinetic law given in eq 4. Plots of pseudo-first-order rate constants $k_{\text {obs }}$ against [Pỵridines] show good linear relationship as shown in Figure 1. and the second-order rate constants $k$. were determined from the slopes of these plots. The second-order rate constants are summarized in Table 1. No third-oder or higher-order terms were detected. and no complications were found in the determination of $k_{\text {stx }}$ and also in the linear plots of eq $4 \mathrm{~b}$. This is suggest that there is no base-cataly sis or noticeable side reactions. and the overall reaction follows the route given by eq 2 . $^{11}$

$$
\begin{aligned}
\text { Rate } & =k_{2}[\text { Py ridines }][\text { Substrates }]=k_{\text {b b }}[\text { Substrates }] \\
& (4 \mathrm{a}) \\
k_{\text {obs }}=k_{2}[\text { Py ridines }] & (4 \mathrm{~b})
\end{aligned}
$$

\begin{tabular}{|c|c|c|c|c|c|}
\hline \multirow[b]{2}{*}{ Solvents } & \multirow[b]{2}{*}{$\mathrm{X}$} & \multicolumn{4}{|c|}{ Y-pyridines $\left(\mathrm{pK}_{a}\right)$} \\
\hline & & $\begin{array}{c}3-\mathrm{OCH}_{3} \\
(4.88)\end{array}$ & $\begin{array}{c}\mathrm{H} \\
(5.25)\end{array}$ & $\begin{array}{l}3-\mathrm{CH}_{3} \\
(5.68)\end{array}$ & $\begin{array}{l}4-\mathrm{CH} \\
(6.02) \\
\end{array}$ \\
\hline \multirow{3}{*}{$\mathrm{MeCN}$} & $4-\mathrm{NO}_{2}$ & 151 & 218 & 352 & 463 \\
\hline & $4-\mathrm{CN}$ & 14.5 & 19.5 & 34.2 & 66.0 \\
\hline & $4-\mathrm{CF}_{3}$ & 1.15 & 1.90 & 3.86 & 6.52 \\
\hline \multirow{3}{*}{$\begin{array}{c}50 \% \\
\mathrm{MeOH}\end{array}$} & $4-\mathrm{NO}_{2}$ & 19.4 & 27.5 & 58.5 & 65.1 \\
\hline & $4-\mathrm{CN}$ & 2.93 & 3.01 & 9.29 & 10.5 \\
\hline & $4-\mathrm{CF}_{3}$ & 0.277 & 0.298 & 0.695 & 0.999 \\
\hline \multirow{3}{*}{$\mathrm{MeOH}$} & $4-\mathrm{NO}_{2}$ & 8.47 & 11.6 & 20.8 & 26.8 \\
\hline & $4-\mathrm{CN}$ & 1.55 & 2.35 & 3.84 & 60.4 \\
\hline & $4-\mathrm{CF}_{3}$ & 0.258 & 0.275 & 0.354 & 0.485 \\
\hline
\end{tabular}

Table 1. The second-order rate constants $\left(k_{2} \times 10^{2}\right)$ for the reaction of 4-X-2,6-dinitrochlorobenzenes with Y-pvridines in MeOH-MeCN mixtures at $25^{\circ} \mathrm{C}$

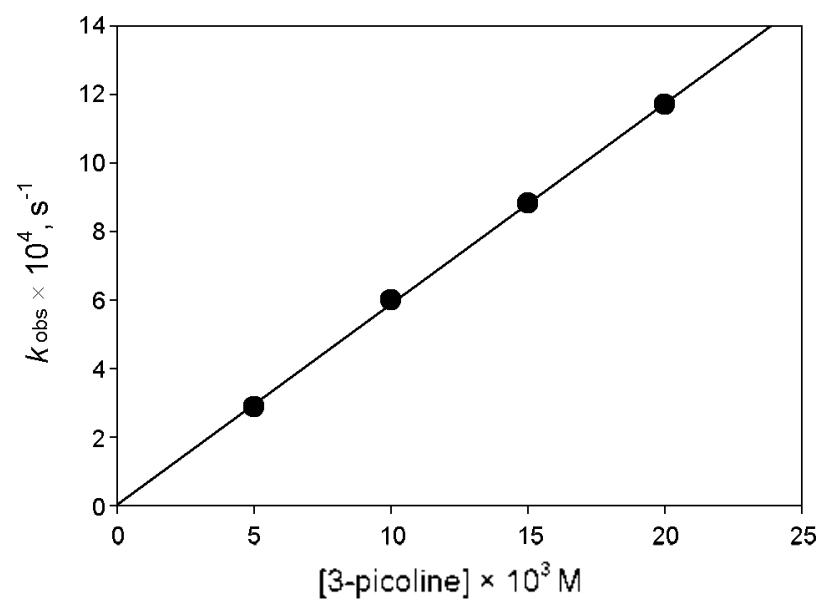

Figure 1. A plot of the observed first-order rate constants $\left(k_{v z s} \times 10^{4}\right.$ $\mathrm{M}^{\cdot} \mathrm{s}^{.1}$ ) against concentration of 3 -picoline for the reaction of 2,4,6-trinitrochlorobenzene with 3-picoline in $50 \% \mathrm{MeOH}-50 \%$ MeCN mistures at $25^{\circ} \mathrm{C}\left(k_{2}=3.52 \times 10^{-1}\right)$.
Medium Effects. The second-order rate constant $\left(k_{2}\right)$ in the Table $\mathrm{l}$ increases in order of $\mathrm{MeCN}>50 \% \mathrm{MeOH}>\mathrm{MeOH}$. The second-order rate constant $\left(k_{2}\right)$ for the reaction of 2.4.6trinitrochlorobenzene with py ridines in acetonitrile decreases with decreasing the basicity of pyridines. i.e.. decreases from $0.463 \mathrm{M}^{-1} \mathrm{~s}^{-1}$ to 0.218 and $0.151 \mathrm{M}^{-1} \mathrm{~s}^{-1}$ as the $\mathrm{p} K_{\mathrm{c}}$ of pyridines decreases from 6.02 to 5.25 and 4.88, respectively. However. the rate constant $\left(k_{2}\right)$ for the reaction of $4-\mathrm{CF}_{3}-2.6$-dinitrochlorobenzene in methanol decreases in a lesser degree with decreasing the basicity of pyridines. i.e.. decreases from $0.485 \times$ $10^{-3} \mathrm{M}^{-1} \mathrm{~s}^{-5}$ to $0.275 \times 10^{-3}$ and $0.258 \times 10^{-3} \mathrm{M}^{-1} \mathrm{~s}^{-1}$ as the $\mathrm{p} K_{\mathrm{a}}$ of py ridines decreases from 6.02 to 5.25 and 4.88 . respectively: Although changes in the overall reactivity with the variation of substituent $\mathrm{Y}$ in pyridine show similar tendency in three substrates. the rate enhancement due to the variation of substituent Y. $k_{4-\mathrm{CH}_{3}} / k_{3} \mathrm{OCH}_{3}$ in methanol is smaller than in acetonitrile solvent: the value of $k_{4} \mathrm{CH}_{3} / k_{3-\mathrm{CCH}_{3}}$ for the reaction of $\mathrm{X}=$ $4-\mathrm{CF}_{3}$ is 5.67 in $\mathrm{MeCN}$. while the value is $1.88 \mathrm{in} \mathrm{MeOH}$. This may be attributed to the reduced nucleophilicity of substituted pyridines in methanol solvent because of the hydrogen bond between nucleophiles (pyridines) and methanol molecule (Scheme 1).

Table 1 also shows that the second-order rate constant $\left(k_{2}\right)$ for the reaction of 2,4.6-trinitrochlorobenzene with pyridines decreases with increasing the methanol volume percent. i.e., decreases from $463 \times 10^{-2} \mathrm{M}^{-1} \mathrm{~s}^{.1}$ in acetonitrile to $26.8 \times 10^{-3}$ $\mathrm{M}^{-1} \mathrm{~s}^{-1}$ in methanol for $\mathrm{X}=4-\mathrm{NO}_{2}$ and $\mathrm{Y}=4-\mathrm{CH}_{3}$. It is noted that the hydrogen bonded pyridine by methanol molecule is less reactive than free pyridine in acetonitrile solvent: the attacking pyridine is a weak nucleophile in methanol. but becomes more reactive in acetonitrile.

The decrease in the second-order rate constant $\left(k_{2}\right)$ by increasing the volume percent of methanol indicates that the ground state (GS) stabilization energy due to the hydrogen bond with methanol solvent is larger than that of transition state (TS) as depicted in Figure 2.

Substituent Effects. The various transition state parameters, Hammett coefficients $\rho_{X}$ and $\rho_{Y}$ values. cross-interaction constant $\rho_{\mathrm{X}}$ (eq. 3). and Brönsted $\beta_{\mathrm{Y}}$ values are summarized in Tables $2-5$. Both the Hammett (for X and $Y$ ) and Brönsted plots show good linearity as shown in Figures 3,4 and 5 . The $\beta_{\mathrm{X}}\left(\beta_{13 \mathrm{k}}\right)$ values were determined by plotting $\log k_{2}$ (MeCN. $\mathrm{MeOH})$ against $\mathrm{p} K_{\mathrm{a}}\left(\mathrm{H}_{2} \mathrm{O}\right)$ of pyridines. This procedure was found to be reliable since the $\mathrm{p} K_{\mathrm{a}}(\mathrm{MeCN})$ varied in parallel with the $\mathrm{p} K_{\mathrm{a}}\left(\mathrm{H}_{2} \mathrm{O}\right)$ with a reasonably constant difference of $7.5\left(=\mathrm{pK}\right.$ a $\left.\left.(\mathrm{MeCN})-\mathrm{p} K_{\mathrm{a}}\left(\mathrm{H}_{2} \mathrm{O}\right)\right)\right)^{15.16}$

Table 1 shows that the rate constant increases in the order of $\mathrm{X}=4-\mathrm{NO}_{2}>4-\mathrm{CN}>4-\mathrm{CF}_{2}$ and also increases in the order of

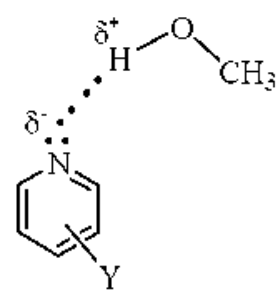

Scheme 1 


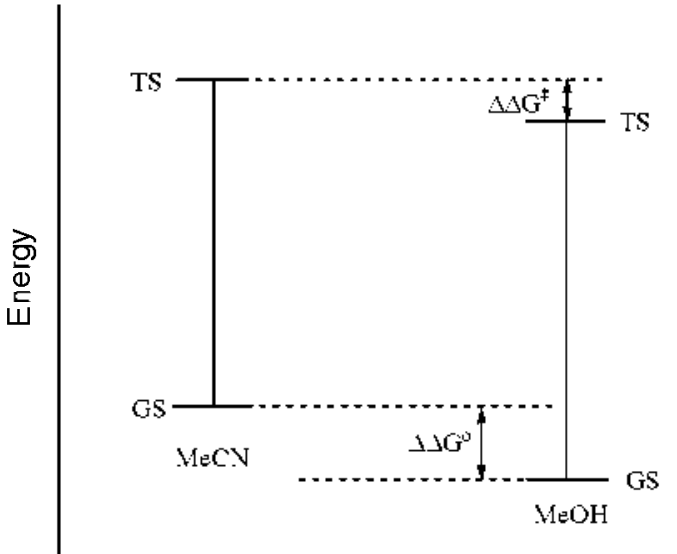

$\Delta \Delta G^{\ddagger}<\Delta \Delta G^{\circ}$ : Important of G.S Hydrogen Bond

Figure 2. Stabilization energy of GS and TS by methanol.

Table 2. Hanunett $p_{y}$ values for the reaction of pyridines with 4-X-substituted-2,6-dinitrochlorobenzenes in MeOH-MeCN mixtures at $25^{\circ} \mathrm{C}$

\begin{tabular}{|c|c|c|c|c|c|c|}
\hline \multirow{3}{*}{ Solvents } & \multicolumn{6}{|c|}{$\mathrm{X}-\mathrm{C}_{6} \mathrm{H}_{3}\left(\mathrm{NO}_{2}\right)_{2} \mathrm{Cl}$} \\
\hline & \multicolumn{2}{|c|}{$\mathrm{X}=\mathrm{CF}_{3}$} & \multicolumn{2}{|c|}{$\mathrm{X}=4-\mathrm{CN}$} & \multicolumn{2}{|c|}{$\mathrm{X}=4-\mathrm{NO}_{2}$} \\
\hline & $\mathrm{PY}_{\mathrm{Y}}$ & $(\mathrm{I})^{a}$ & $P_{Y}$ & $(\mathrm{r})^{4}$ & $p_{Y}$ & $(\mathrm{r})^{a t}$ \\
\hline $\mathrm{MeCN}$ & -2.69 & $(0.987)$ & -2.32 & $(0.972)$ & -1.75 & $(0.986)$ \\
\hline $\begin{array}{c}50 \% \\
\mathrm{MeOH}\end{array}$ & -2.09 & $(0.925)$ & -2.18 & $(0.980)$ & -1.98 & $(0.947)$ \\
\hline $\mathrm{MeOH}$ & -0.97 & $(0.945)$ & -2.09 & $(0.992)$ & -1.83 & $(0.974)$ \\
\hline
\end{tabular}

"Correlation coefíicient

Table 3. Hammett $p_{\mathrm{x}}$ values for the reaction of $4-\mathrm{X}$-substituted2,6-dinitrochlorobenzenes with pyridines in $\mathrm{MeOH}-\mathrm{MeCN}$ mixtures at $25^{\circ} \mathrm{C}$

\begin{tabular}{|c|c|c|c|c|}
\hline \multirow{3}{*}{ Solvents } & \multicolumn{4}{|c|}{$\mathrm{Y}-\mathrm{C}_{6} \mathrm{H}_{5} \mathrm{~N}$} \\
\hline & $\mathbf{Y}=3-\mathrm{OCH}_{3}$ & $\mathbf{Y}=\mathrm{H}$ & $\mathbf{Y}=3-\mathrm{CH}_{2}$ & $\mathbf{Y}=4-\mathrm{CH}_{3}$ \\
\hline & $\rho x \quad(r)^{\sigma}$ & $\mathrm{PX} \quad(\mathrm{r})^{\sigma}$ & $\mathrm{PX}_{\mathrm{X}} \quad(\mathrm{r})^{\sigma}$ & $\mathrm{PX} \quad(\mathrm{r})^{a}$ \\
\hline $\mathrm{MeCN}$ & $8.83(0.999)$ & $8.58(0.999)$ & $8.17(0.999)$ & $7.71(0.999)$ \\
\hline $\begin{array}{c}50 \% \\
\mathrm{MeOH}\end{array}$ & $7.69(0.998)$ & $8.19(0.999)$ & $8.02(0.995)$ & $7.56(0.997)$ \\
\hline $\mathrm{MeOH}$ & $6.32(0.999)$ & $6.77(0.996)$ & $7.37(0.995)$ & $7.26(0.989)$ \\
\hline
\end{tabular}

${ }^{a}$ Correlation coefficient

Table 4. Cross-interaction constants, pxy, for the reactions of $4-X$ 2,6-dinitrochlorobenzenes with Y-substituted pyridines in $\mathrm{MeOH}$ MeCN mistures at $25^{\circ} \mathrm{C}$

\begin{tabular}{cr}
\hline Solvents & PXY \\
\hline MeCN & 3.95 \\
$50 \% \mathrm{MeOH}$ & 0.46 \\
$\mathrm{MeOH}$ & -3.44 \\
\hline
\end{tabular}

$\mathrm{Y}=4-\mathrm{CH}_{3}>3-\mathrm{CH}_{3}>\mathrm{H}>3-\mathrm{OCH}_{3}$. This result indicates that the rates are faster for a stronger nucleophile $\left(\delta \sigma_{\mathrm{Y}}<0\right)$ and the substrate (SDC) with a stronger electron-withdrawing group in phenyll ring $\left(\delta \sigma_{\mathrm{Y}}>0\right)$. The large positive $\rho_{\mathrm{Y}}$ and $\beta_{\mathrm{Y}}$ values and the large negative $\rho_{Y}$ values indicate that the negative charge is developed in the substrate phenyl ring at the TS and
Table 5. Brönsted $\beta$ values for the reaction of 4-X-2,6-dinitrochlorobenzenes with pyridines in MeOH-MeCN mistures at $25^{\circ} \mathrm{C}$

\begin{tabular}{|c|c|c|c|c|c|c|}
\hline \multirow{3}{*}{ Solvents } & \multicolumn{6}{|c|}{$\mathrm{X}-\mathrm{C}_{6} \mathrm{H}_{5}\left(\mathrm{NO}_{2}\right)_{2} \mathrm{Cl}$} \\
\hline & \multicolumn{2}{|c|}{$\mathbf{X}=\mathrm{CF}_{3}$} & \multicolumn{2}{|c|}{$\mathbf{X}=4-\mathrm{CN}$} & \multicolumn{2}{|c|}{$\mathbf{X}=4-\mathrm{NO}_{2}$} \\
\hline & $\beta_{Y}$ & $(\mathrm{I})^{a}$ & $\beta_{Y}$ & $(r)^{a}$ & $\beta_{Y}$ & $(\mathrm{I})^{n}$ \\
\hline $\mathrm{MeCN}$ & 0.67 & $(0.999)$ & 0.57 & $(0.985)$ & 0.43 & $(0.998)$ \\
\hline $50 \% \mathrm{MeOH}$ & 0.53 & $(0.964)$ & 0.57 & $(0.933)$ & 0.50 & $(0.976)$ \\
\hline $\mathrm{MeOH}$ & 0.24 & $(0.963)$ & 0.52 & $(0.999)$ & 0.46 & $(0.994)$ \\
\hline
\end{tabular}

${ }^{\pi}$ Correlation coefficient

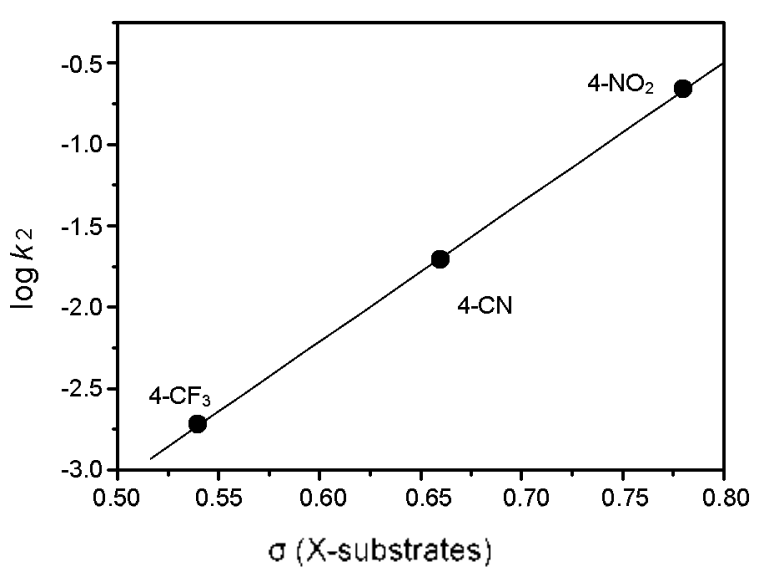

Figure 3. Typical Hammett plot for the reaction of 4-substituted2,6 -dinitrochlorobenzenes with pyridine in $\mathrm{MeCN}$ solvent at $25^{\circ} \mathrm{C}$ $(\rho \mathrm{x}=8.58)$

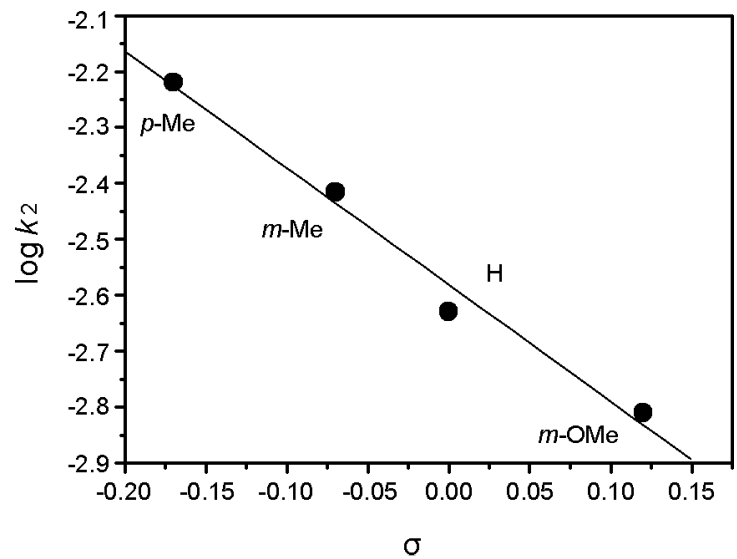

Figure 4. Typical Hammett plot for the reaction of Y-pyridines with 4-cyano-2,6-dinitrochlorobenzenes in $\mathrm{MeOH}$ solvent at $25^{\circ} \mathrm{C}$ $\left(\rho_{y}=-2.09\right)$.

the anion intermediate (Meisenheimer complex) is stabilized through the delocalization of negative charge by resonance as shown in Scheme 2.

The sign of pxy shown in Table 4 is changed. and the value of $p_{x y}$ is reduced as the volume percent of methanol increase. This is very unexceptional result because it is conflicted with the known mechanistic criteria. The positive $\rho_{\mathrm{xy}}$ value in $\mathrm{MeCN}$ solvent system indicates that the rate limiting step is bond formation process. and is in good agreement with an 


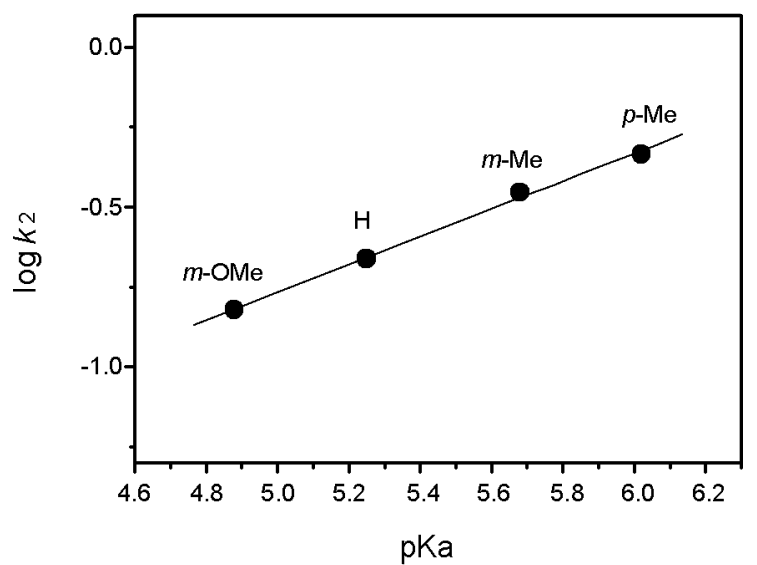

Figure 5. Typical Bronsted plot for the reaction of 4 -nitro-2,6-dinitrocllorobenzene with pyridines in $\mathrm{MeCN}$ solvent at $25^{\circ} \mathrm{C}(\beta=0.43)$.
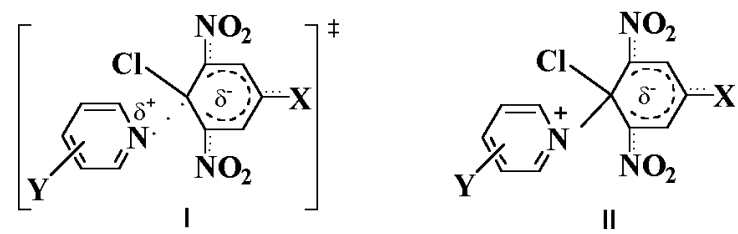

Scheme 2. Transition state structure (I) and Meisenheimer complex (II).

addition transition state and Meisenheimer complex (Scheme 2) in this study such as nucleophilic substitution and addition reactions. ${ }^{17}$ However, negative $\rho_{X Y}$ value in $\mathrm{MeOH}$ solvent system reveals that the hydrogen bonded pyridine by $\mathrm{MeOH}$ is less reactive than free py ridine in MeCN. From the reversal of the sign in $\rho_{\mathrm{XY}}$ on going from $\mathrm{MeCN}$ to $\mathrm{MeOH}$ solvent. we can estimate zero ( 0 ) value of $\rho \mathrm{xy}$ at near $50 \sim 60 \% \mathrm{MeOH}$ (or $40 \sim 50 \% \mathrm{MeCN}$ ) solvent mixture which is an isokinetic solvent mixture. The isokinetic solvent mixture observed in the present work is the result of compensation for the substituents effects in the substrate and nucleophilic. ${ }^{18}$

\section{Conclusion}

The electrophilic cataly sis by methanol may be ascribed to the formation of hydrogen bonds between alcoholic hydrogen and nitrogen of pyridines in ground state. We found that the isokinetic solvent mixtures corresponding to $\mathrm{pxy}_{\mathrm{AY}}=0$. where the substituent effects of the substrate and nucleophile are compensated each other. Based on the transition state parameters ( $\rho$ s. $\rho$ N. $\beta$. and $\rho \mathrm{XY}$ ) and solvent effects. we conclude that the reaction proceeds via $\mathrm{S}_{\mathrm{N}} \mathrm{Ar}$-Ad.E mechanism.

\section{Experimental Section}

Materials. 2,4,6-Trinitrochlorobenzene (TCI-GR) 4-cyano2,6-dinitrochlorobenzene (Alfa Aesar-GR), 4-trifluoromethyl2.6-dinitrochlorobenzene (Alfa-Aesar-GR), and pyridines (Aldrich-GR) were used commercial grade ( $>98 \%$ ). Merk GRgrade $(<0.1 \%$ water $)$ methanol and acetonitrile were used without further purification. Distilled water was redistilled with Buchi Fontavapor 210 and treated using ELGA UHQ PS to obtain specific conductivity of less than $1.0 \times 10^{-6}$ mhos $/ \mathrm{cm}$.

Kinetics. Rates were measured conductimetrically at least in duplicate as in previous work. ${ }^{19}$

Product Analysis. Pyridinium salts were liberated quantitatively and identified as one of the reaction products by comparison of the UV-Vis spectra after the completion of the reactions with those of the authentic samples under same reaction conditions. For example. $\varepsilon=6092 \mathrm{M}^{-1} \mathrm{~cm}^{-1}$ at $376 \mathrm{~nm}$ for pyridinium salt $\left(\mathrm{X}=4-\mathrm{NO}_{2}, \mathrm{Y}=\mathrm{H}\right)$.

\section{References}

1. (a) Bemasconi, C. F. Acc. Chem. Res. 1978, 11, 147. (b) Paradisi, C. In Complehensive Oiganic Symthesis: Trost, B. M.: Fleming, I., Ed.; Pergmon Press: Oxford, 1991; Vol. 4, p 423.

2. Wu, Z; Glaser, R. J. An. Chem. Soc. 2004, 126, 10632

3. (a) Miller, I . Aimatic Nicleophilic Substitution Reaction. Elsevier: London, 1968. (b) Ross, S. D. Prog. Phws. Org. Chent. 1963, 1, 31.

4. Terrier, F. Anontatic Nucleophilic Substitution Reaction; VCH Publishers: New York, 1991.

5. Bemasconi, C. F. IITP hit. Rev Sci. Org. Chent. Ser. 1 1973, $3,33$.

6. Lee, H. W; Lee, I. J. Korean Chent. Soc, 1978, 22, 221

7. (a) Koniglio, B. O. et al, J. Chem. Soc. 1966, 152; (b) Parker, A. J. Ibid. 1961, 4398.

8. (a) Kingsbury, C. A. J. Oig Chem 1964, 29, 3262; (b) Suchkova, L. A.; Suchkova, L. A. Reahts. Sposobnost Oigan. Soed. 1968, 5 , 310 ; (c) Bullestreri, F. P. et al. J. Org. Chem. 1977, $12,1415$.

9. Banjoko, O.; Babatunde, I. A. Tetrahedron 2004, 60, 4645 .

10. Mancini, P. M.: Fortunato, G. G.; Vottero, L. R. J. Phys. Oig. Chem. 2004, 17, 138.

11. Koh, H. J.: Han, K. L.: Lee, H. W.; Lee, I. J. Org. Chem 1998 , 63,9834

12. Kang, D. H.; Koo, I. S.; Lee, T. G.; Lee, I. J. Korem Chem. Soc. $1985,29,565$

13. (a) Oh, H. K; Yang, T. H; Sung, D. D.; Lee, I. J. Chem. Soc. Pewin Trans. 2 2000, 101 . (b) Oh, H. K.; Kim, T. S : Lee, H. W: Lee, I. J. Chem. Soc. Pethin Trans. 2 2002, 282. (c) Oh. H. K.; Yang, J. H.; Hwang, Y. H.; Lee, H. W.; Lee, I. Bull. Korean Chent. Soc. 2002, 23, 221. (d) Oh, H. K.: Yang, J. H.; Lee, H. W.; Lee, I. J. Oig. Chem 2000, 65, 2188.

14. (a) Lee, I Adw Phys. Org. Chem 1992, 27, 57; (b) Lee, I. Chent. Soc. Rev. 1990, 19, 317, (b) Jeong. K. S.: Oh, H. K. Bull. Korean Chem. Soc. 2009, 30, 253 (c) Park, S. Y.: Oh, H. K. Bull Korean Chem. Soc. $2009,30,749$.

15. Hwang, T.: Yang, K.; Koo, I. S.; Sung, D. S.: Lee, I. Bull. Korean Chem. Soc. 2006, 27, 733

16. (a) Ritchie, C. D. In Solnte-Solvent Interactions; Coetzee, J. F: Ritchie, C. D., Eds.: Marcel Dekker: New York, 1969: Chapter 4. (b) Coetzee, J. F. Progress in Plysical Organic Chemistry; Streitwieser, A.; Jr., Taft, R. W., Eds.: Wilev: New York, 1967; Vol. 4, pp 54-92. (c) Spillane, W. T.; Hogan, G.: McGrath, P.; King, T.; Brack, C. J. Chem. Soc, Perkin Trans. 2 1996, 2099. (d) Lee, I; Kim, C. K.; Han, I. S.; Lee, H. W.; Kim, W. K.; Kim, Y. B. J. Phss. Chem. B 1999, 103, 7302.

17. (a) Oh, H. K, Kim, I. K, Sung, D. D; Lee, I. Bull Konean Chem. Soc 2005, 26, 64l (b) Lee, I.; Lee, H. W. Collect Czech. Chem. Commm 1999, 64, 1529. (c) Lee, I. Chem. Soc. Rev. 1990, 19, 317. (d) Lee. I. Chem. Soc. Rew 1995, 24, 223.

18. (a) Lee, I. J. Phus Oig. Chem 1996, 9,661 (b) Shpanko, I. V; Kim, S. I.: Koh, J. K.: Lee, I. Bull Korem Chem Soc. 1995, 16, 533.

19. (a)Bentley, T. W. Carter, G. E; Harris, H. C. J. Chent Soc, Pewin Trans. 2 1985, 983 (b) Bentley, T. W. Harris, H. C. J. Chem. Soc. Perkin Trans. 2 1986, 619. (c) Bentley, T. W; Carter, G. E.; Koo, I. S. J. Chent. Soc. Chent Conmm 1988, 41. (d) Yang, K, Koo, I. S.; Lee, I.: Jo, D.-S. Bull Konan Chem. Soc. 1994, 15, 280. 